I f you search the back catalogue of any major songwriter, lyricist or singer you will find songs about leaving; leaving home, a lover, friends and buddies; possibly on a jet plane, a midnight train or by some other form of transport. Sometimes it is the end of a relationship which heralds the departure of one of the protagonists. Strangely, in some songs the leaving is lamented, whilst in others it is celebrated or winsomely recalled with fondness and just a frisson of sadness. But those songs have assumed another meaning following the pandemic caused by COVID- 19 .

\section{Maintaining balance}

Currently, the business of dentistry is experiencing very changeable times such that some dentists, when they survey the future and reflect on the elapsed time since March 2020, may feel an urge to change their own situation and possibly even their career. In unprecedented times there can be no certainty beyond the population's ongoing need for dental treatment and their reliance on the services of those who are registered to provide it. When assessing the future, every clinician has to judge for themselves and decide how they intend to service that demand whilst balancing income, job satisfaction and their preferred working environment in order to maintain the standards expected of them by the GDC.
The polar opposite situation arises when a change in circumstances is simply thrust upon you, and you are told that your services are no longer required, or the conditions and the percentage of the fees (or salary) you receive are altered. If these changes are imposed with little or no consultation, financial decisions can be more difficult to deal with or plan and the emotional legacy can be overwhelming.

\section{Moving from your present location} Many reasons may prompt you to move - retirement, family circumstances, childcare, following a partner's new working arrangements or simply the desire for a change of scene and the need for something new.

The reason might be work related - the hours, the type of work, a lack of opportunity to develop new skills or the atmosphere in the workplace, its culture, or indeed, dysfunctional relationships within the dental team.

One thing that has emerged as a recent phenomenon are the challenges faced by dentists providing treatment that involves aerosol generating procedures (AGPs), fallow time and the necessity to wear layers of personal protective equipment which can be particularly uncomfortable during warm weather when the humidity is high. Many clinicians are saying that it is difficult to ignore that they feel uncomfortable wearing personal protective equipment (PPE) and this is affecting sustained concentration and their ability to do their job well. The operating procedures make it increasingly difficult to maintain fine motor skills for long periods of time without feeling extremely tired, which in turn can challenge professional competence and undermine personal confidence.

For some, professional satisfaction has evaporated - the fun has simply gone out of the job. Others are working shift patterns that are less conducive to a good work/life balance whilst they try to compensate for the earnings lost during lockdown and because of the mandatory fallow time between patients in their surgery. In addition, the new rotas that safely modify the flow of patients through the practice mean that together with social distancing, there is little or no opportunity to enjoy the company of colleagues between patients. Obtaining second opinions and catching up with other members of the dental team is often a much needed safety valve to the stress that dentists experience when managing a difficult patient or dealing with a case that turns out to be more complicated than expected.

With so many changes and uncertainties confronting the business of dentistry it would seem quite reasonable to keep an open mind about new opportunities and trust your own intuition to find ways to rekindle the enjoyment in your chosen profession. If that involves leaving your practice, for whatever reason, here 
are some things to think about before you start the process.

\section{Continuity of patient care}

Patients do not like surprises and depending how long you have been their dentist, they may be very reluctant, even apprehensive if they have built up trust with you, to simply move to another colleague to complete their treatment.

Therefore, try if possible, to ensure that you finish any current course of treatment you have prescribed before you leave. Remember it can be difficult for someone else to complete the treatment you have started. Another dentist may not always agree with your clinical opinion and a very different approach to the patient's treatment could cause problems. Because your management of a particular patient may differ from the next dentist, meticulous record keeping is essential, particularly if you have agreed with the patient to monitor a situation rather than immediately start interventive treatment; your notes should accurately reflect that discussion.

In anticipation of your intention to leave a practice, make sure you have undertaken periodontal assessments and recorded BPE scores and, when indicated, recorded full pocket depths and prescribed any necessary periodontal therapy. Likewise ensure you have taken radiographs at appropriate intervals and prescribed treatment as a result of the findings.

Think carefully about orthodontic treatment, fixed or aligner cases cannot be finished quickly or easily passed on to another clinician, especially if nobody else in the practice is undertaking that type of treatment. Such patients must not be abandoned, and steps will need to be taken to transfer your duty of care to another appropriately trained colleague, always with the patient's agreement.

Ideally, avoid embarking upon any new elaborate treatment plans once you have decided to leave. Indeed, the practice may not want to book new patients for you - which could well have implications for your income and will need to be budgeted for.

\section{Contracts}

Even if you have no written contract with your current practice owner, the recognised industry standard (custom and practice) is to give three months' notice of your intention to leave. This affords you time to complete outstanding treatment and similarly allows the practice to find your successor without impacting too heavily on the cash flow of the business.

If you have a written contract it is likely to contain a restrictive covenant. This needs to be read carefully and fully understood and, if you are planning on working elsewhere, you will need to abide by the terms that you have agreed. They have been written into the associate contract to protect the goodwill of the practice you are leaving.

\section{Patient matters}

If a patient locates your new whereabouts through their own researches that is a different matter, patients are entitled to freely chose who they are treated by and where, but ugly disputes can arise if it can be demonstrated that you have been intentionally poaching patients by attracting a following and giving them your contact details of your new workplace.

\section{'In unprecedented times there can be no certainty beyond the population's ongoing need for dental treatment and their reliance on the services of those who are registered to provide it'}

As we all know only too well, no one is infallible and even in the most experienced hands treatment can fail and work which the patient has paid for may need to be redone. This is a common enough scenario and one which vividly illustrates the benefits of leaving a practice on the best possible terms. Particularly since the words a colleague chooses to use with the patient, when identifying a problem that has arisen from treatment you have provided, can either protect your reputation or cast doubt in the patient's mind as to your competence. This could in turn create dissatisfaction with your care, leading to a complaint, especially if the patient is subsequently charged for remedial treatment.

The solution in such situations lies in a retention fee. This is a financial arrangement made with the practice owner to leave a set fee for an agreed period on account to be used in the event of any remedial treatment being required after your departure. You can ask for a breakdown of any fees used in this way at the culmination of the agreed period. Many a patient complaint has been averted by the willing provision of remedial treatment utilising this measure.

Furthermore, if you were to be unfortunate and a complaint is received at your former practice, ensure that you ask the principal to alert you to this so you can provide your input and observations to achieve resolution, having contacted your professional indemnity organisation for assistance.

\section{Leave a forwarding address}

In light of the above, do not go 'MIA' (missing in action); instead always make sure that you leave contact details with your former principal that allows them to contact you after your departure. Take a moment to contact your indemnity provider that you are moving practice or even leaving dentistry.

If your decision is less radical and you are only revising the number of hours you are working in a new practice, let your indemnity provider know so that they can advise you of any adjustment which may be needed to your policy.

It can come as a surprise to some dentists that even after they have ceased to be a dentist and come off the register, they remain accountable for their acts and omissions (treatment they have provided, or failed to provide) whilst they were practising.

For this reason, occurrence-based indemnity cover is the optimal product, providing ultimate reassurance and peace of mind when you are no longer earning income. The jargon surrounding the terms and conditions of indemnity can be baffling and, if you have any doubt as to the type of indemnity you have, ask your provider to explain. 'Occurrence-based', simply put means that if you were indemnified at the time of the 'occurrence' (the issue that triggered the claim) and in the correct category of cover (paying the right amount of money) you can call on your indemnity provider for assistance with the claim, and its financial implications for you, in perpetuity. Bleakly, but responsibly, this even extends beyond your death, until your estate has been closed.

The situation is altogether different if your indemnity is provided by a claims-made insurer. Here the concept of 'run-off cover' kicks in and if you are in any doubt about what this means and, as it is beyond the scope of this article, you will need to discuss this subject with your insurer. Suffice it to say that BDA Indemnity provides an occurrencebased insurance policy to ensure members are protected in the future for the treatment done whilst their policy was in operation.

\section{Conclusion}

A change can be as good as a rest and by taking on board the advice given above, you can move on and perhaps then rekindle your mojo and enjoy life again in this new COVID-19 climate. *

https://doi.org/10.1038/s41404-020-0510-9 